\title{
BURNOUT EM RESIDENTES DE ANESTESIOLOGIA: UMA REVISÃO SISTEMÁTICA
}

\author{
Categoria: SAÚDE COLETIVA/ EPIDEMIOLOGIA
}

\section{CENTRO UNIVERSITÁRIO SÃO CAMILO}

\author{
Silva, L.L.'; \\ Canga, L.A. ${ }^{\text {; }}$; \\ Saltão, R.Q. ${ }^{1}$; \\ Lima, V.G.B.'; \\ Trombeta, L.C. ${ }^{1}$; \\ Tedesco, M. ${ }^{2}$
}

${ }^{1}$ ACADÊMICOS DO CENTRO UNIVERSITÁRIO SÃO CAMILO

${ }^{2}$ RESIDENTE DE ANESTESIOLOGIA DA FACULDADE DE MEDICINA DO ABC

Rua Tupiniquins, 51 - Jardim Bandeirantes - Ribeirão Pires - SP

CEP: 09440-010

(11) 97654-9893 e-mail: leandroleal.silva.lls@gmail.com ou leandro.leal@aluno.saocamilo-sp.br 


\section{BURNOUT EM RESIDENTES DE ANESTESIOLOGIA: UMA REVISÃO SISTEMÁTICA}

Categoria: SAÚDE COLETIVA/ EPIDEMIOLOGIA

DESCRITORES: Burnout; residentes de anestesiologia; estresse em anestesiologia 


\title{
BURNOUT EM RESIDENTES DE ANESTESIOLOGIA: UMA REVISÃO SISTEMÁTICA
}

\author{
Silva, L.L. ${ }^{1}$; Canga, L.A. ${ }^{1}$; Saltão, R.Q.' ${ }^{1}$ Lima, V.G.B. ${ }^{1}$; Trombeta, L.C. ${ }^{\text {; }}$ Tedesco, M. ${ }^{2}$ \\ ${ }^{1}$ ACADÊMICOS DO CENTRO UNIVERSITÁRIO SÃO CAMILO \\ ${ }^{2}$ RESIDENTE DE ANESTESIOLOGIA DA FACULDADE DE MEDICINA DO ABC
}

\section{RESUMO}

INTRODUÇÃO: Os profissionais da área da saúde, principalmente os médicos, possuem um alto grau de responsabilidade, logo estão passíveis de maiores efeitos estressantes. Do mesmo modo que o estresse pode ser benéfico, pode não ser, sobretudo quando for em alto grau, com enfrentamento pessoal ineficaz e em momentos de situações adversas na profissão. Ademais, as constantes mudanças na medicina e no comportamento do paciente ao longo do tempo fez com que os médicos se tornassem mais acometidos pela síndrome psicológica conhecida como Burnout. Dentre as diversas áreas da medicina, o anestesiologista é o profissional que mais é acometido por essa síndrome devido as condições em que é exposto diariamente na prática de sua atividade, e possui diversos fatores agravantes do estresse. Não obstante, os recém-formados e residentes ainda são os sujeitos mais predispostos a desenvolver Burnout por não estarem acostumados às novas rotinas.

OBJETIVO: Considerando que os anestesistas são os principais profissionais acometidos pelo Burnout e ser residente ou recém-formado constitui um importante fator de risco para o desenvolvimento da síndrome, objetiva-se avaliar a possível incidência e as características do Burnout nos médicos residentes de anestesiologia.

METODOLOGIA: pesquisa bibliográfica sistemática sobre o tema Burnout em residentes de anestesiologia utilizando a Bireme e PubMed. O trabalho foi realizado de acordo com os critérios de PRISMA e contou com a análise para síntese qualitativa de 19 estudos - apenas 1 estudo foi excluído na triagem por não estar associado ao tema da pesquisa de acordo com a análise do respectivo resumo.

RESULTADOS: diversos estudos relataram que os residentes de anestesiologia são os indivíduos com maiores riscos de desenvolver Burnout, e é um dos problemas mais comuns de diversas instituições. Na maioria dos estudos o sexo feminino foi considerado como um fator de risco maior, apesar de não ser unânime dentre os estudos analisados.

CONCLUSÃO: Os residentes de anestesiologia estão propensos a desenvolveram a síndrome do Burnout por diversos fatores de risco diretamente relacionadas com suas atividades diárias, e apesar de existir meios para lidar com essa problemática, são ferramentas superficiais e que não abrangem o profissional que necessita de apurado cuidado.

DESCRITORES: Burnout; residentes de anestesiologia; estresse em anestesiologia 


\section{BURNOUT EM RESIDENTES DE ANESTESIOLOGIA: UMA REVISÃO SISTEMÁTICA}

\section{INTRODUÇÃO}

Os profissionais que lidam com a saúde, principalmente o médico, possuem um alto grau de responsabilidade e, consequentemente, estão passíveis de maiores efeitos estressantes, sobretudo quando houver a possibilidade de ocorrer erros que podem influenciar de modo negativo na vida do paciente. [1] Sabe-se que o estresse pode ser um fator que torna o profissional mais cuidadoso em suas ações e que garante bem-estar e sensação de confiança após o enfrentamento da situação que o estimulou, todavia, altos graus de estresse estão relacionados a estratégias de enfrentamento ineficazes, diminuindo a satisfação e a saúde mental do médico. [1-2] Além disso, com as constantes atuais mudanças da medicina e do mercado de trabalho, com o sensacionalismo da mídia sobre esse profissional bem como as mudanças comportamentais dos pacientes ao longo do tempo, é crescente o número de acometidos por uma síndrome psicológica, conhecida como Burnout. [2-3]

O termo Burnout foi originalmente utilizado em 1974 por Herbert Freudenberger para representar o resultado negativo do desequilíbrio entre a vida no trabalho, alto estresse e a insatisfação com o trabalho e foi amplamente estudado até que, em 1999, Christina Maslach e Michael Leiter deram a definição da Síndrome de Burnout: síndrome composta pelos tripés alta exaustão emocional (EE), alta despersonalização (DP) e baixa realização pessoal (PA) [4]. A EE é um sentimento de fadiga em relação ao trabalho; a DP é a tentativa de defesa de separar-se do trabalho, e a baixa PA representa um sentimento de frustração com as realizações relacionadas ao trabalho [2], e o critério padrão ouro para avaliar a síndrome de Burnout é o Maslach Burnout Inventory (MBI) criado por Maslach e Jackson que consiste de um questionário com 22 questões a serem respondidas sobre sentimentos em relação ao trabalho e à frequência dos sintomas, pontuando os resultados. [4]

A anestesiologia é atualmente uma das áreas médicas de maior risco ao desenvolvimento de Burnout, pois expõe os médicos diariamente a altas responsabilidades e situações estressantes e potencialmente fatais; cargas horárias extensas (que se estendem muitas vezes aos finais de semana e datas comemorativas), privação do sono; relações interpessoais exigentes; alteração da homeostasia do paciente de modo repentino (sobretudo em casos de emergência), entre outros. $[1,2]$

Apesar da Síndrome de Burnout ser considerada de caráter crônico, ela tem um desenvolvimento agudo que se assemelha à depressão, no entanto, a depressão afeta a vida pessoal do indivíduo, fora do local de trabalho, enquanto que o Burnout é específico do ambiente de trabalho e está fortemente associada ao comprometimento entre os membros da equipe de trabalho, resultando em queda da qualidade das atividades desenvolvidas. [1-3] Diversos estudos demonstram que os jovens médicos (recém-formados e residentes) têm maiores propensões a desenvolverem Burnout 
visto que esse período é o de maior hostilidade na carreira médica, expondo o indivíduo a altos níveis de estresse a qual não estava habituado e com alto grau de responsabilidade, sendo que o início do desenvolvimento dessa síndrome tem características depressivas, além de raiva crônica, distúrbios do sono e conflitos familiares. [3,4]

\section{OBJETIVOS}

Considerando que os anestesistas são os principais acometidos pela síndrome de Burnout e que os jovens têm mais fatores predisponentes à síndrome, o objetivo desse trabalho é avaliar possível incidência e as características do Burnout nos médicos residentes de anestesiologia visto que não há na literatura uma revisão sistemática voltada a apenas este público.

\section{MÉTODOS}

Foi realizada uma pesquisa bibliográfica sistemática pela Internet sobre o tema Burnout em residentes anestesiologistas utilizando a Biblioteca Virtual em Saúde (http://bvsalud.org/) e o PubMed (https://www.ncbi.nlm.nih.gov/pubmed/). A pesquisa foi realizada de acordo com recomendações metodológicas da declaração PRISMA (Principais Itens para Relatar Revisões sistemáticas e Meta-análises, do inglês Preferred Reporting Items for Systematic Reviews and MetaAnalyses) para relatar revisões sistemáticas (Figura 1).[5,6]

A pesquisa incluiu inicialmente todos os tipos de estudos publicados sob a forma de artigo científico datados de 2013 a 2018 na Biblioteca Virtual em Saúde (BVS) sob os descritores 'Burnout' AND 'anesthesiology' AND 'residents' (foram aplicados filtros: texto completo disponível e data - 2013 à 2018) e com os descritores 'anesthesiology' AND 'resident' AND 'Burnout' com aplicação de filtro 'Esgotamento profissional' como assunto principal. No PubMed foi utilizado os descritores 'Burnout' AND 'anesthesiologist' AND 'residents" e não foram aplicados filtros. Das pesquisas, apenas um artigo científico foi excluído por não associação entre Burnout e residente de anestesiologia, segundo leitura do próprio resumo do artigo. Foram selecionados 19 artigos, os quais os autores passaram para a fase de leitura dos textos completos e fichamentos dos dados.

Como o objetivo dessa revisão sistemática é de fornecer amplas informações a respeito da incidência e características do Burnout nos médicos residentes de anestesiologia, não foi realizada a meta-análise do assunto. 


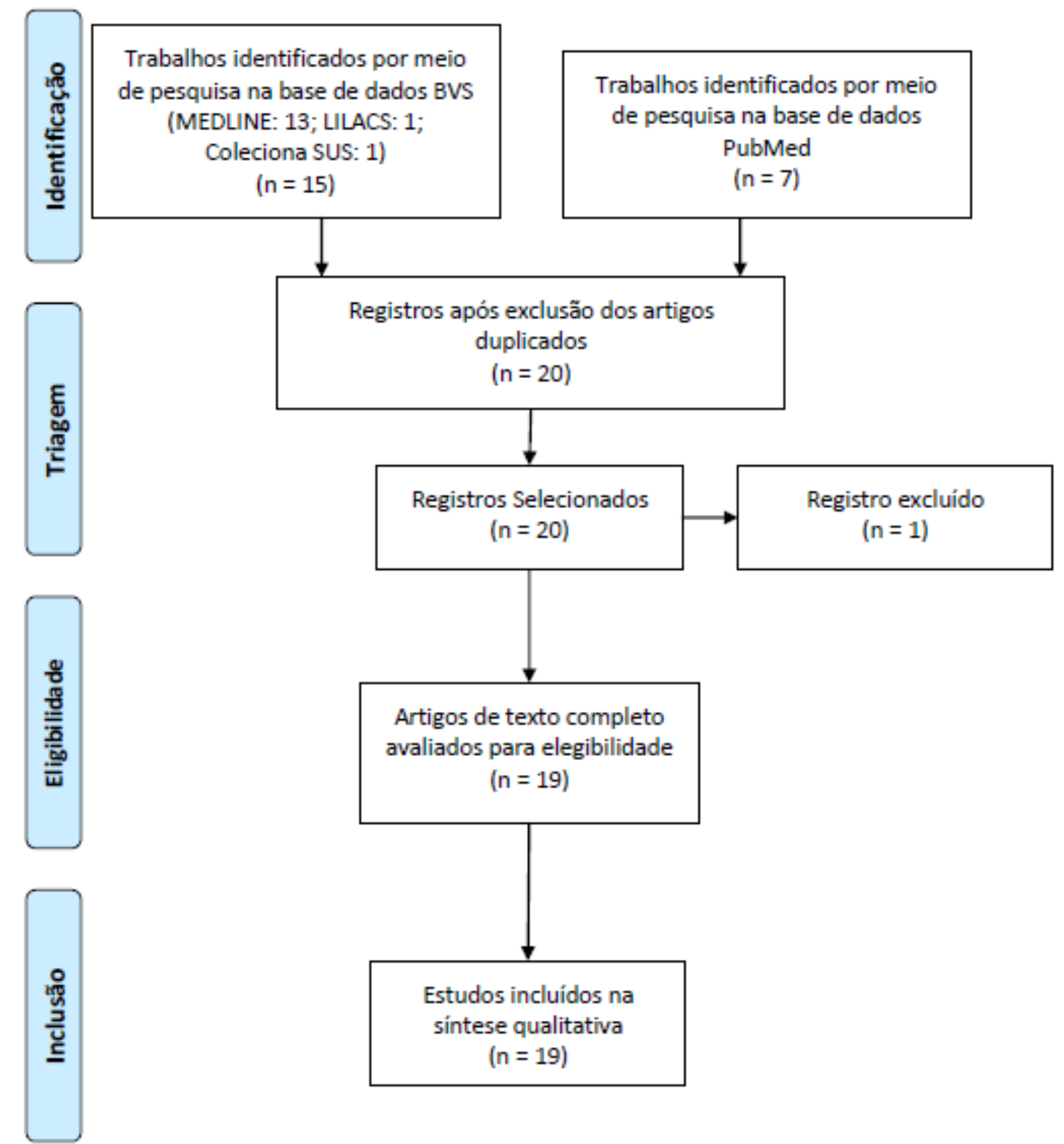

Figura 1: Representação esquemática dos métodos de identificação, triagem, elegibilidade e inclusão de trabalhos na revisão, adaptada de acordo com o PRISMA Flow Diagram [5]

\section{RESULTADOS}

Para melhor apresentação dos dados dos artigos analisados, há a seguir um quadro comparativo com as principais informações dos trabalhos, como autor principal, ano de publicação, país, questionário/ método aplicado, público analisado/ no de participantes, conclusão sintética dos artigos e limitações do estudo. 


\begin{tabular}{|c|c|c|c|c|c|c|}
\hline $\begin{array}{c}\text { Autor } \\
\text { principal }\end{array}$ & $\begin{array}{c}\text { Ano de } \\
\text { publicação }\end{array}$ & País & $\begin{array}{l}\text { Questionário/ } \\
\text { método } \\
\text { aplicado }\end{array}$ & $\begin{array}{c}\text { Público } \\
\text { analisado/ } \mathrm{n} \text { de } \\
\text { participantes }\end{array}$ & Conclusão sintética do artigo & Limitações de Estudo \\
\hline $\begin{array}{l}\text { Benzon et } \\
\text { al. [7] }\end{array}$ & 2018 & EUA & $\begin{array}{l}\text { Questionário de } \\
\text { própria autoria } \\
\text { desenvolvido } \\
\text { em um banco de } \\
\text { dados, com- } \\
\text { posto por } 21 \\
\text { questões, envia- } \\
\text { dos por e-mail. }\end{array}$ & $\begin{array}{l}\text { Residentes de } \\
\text { anestesiologia } \\
\text { pediatrica:56 }\end{array}$ & $\begin{array}{l}\text { O único ponto que o artigo cita Burnout é no } \\
\text { fato que os resultados obtidos em relação a } \\
\text { alta frequência de erros médicos relatados } \\
\text { mostram a necessidade de pesquisa se os } \\
\text { erros são realmente decorrentes da má } \\
\text { supervisão ou se podem estar associados a } \\
\text { depressão, fadiga ou Burnout como a } \\
\text { origem real do problema levantado. }\end{array}$ & $\begin{array}{l}\text { Foram pesquisados } \\
\text { apenas bolsistas de } \\
\text { anestesiologia pediátri- } \\
\text { ca e, portanto, não se } \\
\text { pode generalizar os } \\
\text { achados para diferen- } \\
\text { tes bolsas de estudo de } \\
\text { anestesiologia. }\end{array}$ \\
\hline $\begin{array}{l}\text { Govêia, } \\
\text { Catia Sousa } \\
\text { et al. [8] }\end{array}$ & 2018 & Brasil & $\begin{array}{l}\text { Estudo de corte } \\
\text { transversal - } \\
\text { amostra por } \\
\text { conveniência. } \\
\text { Correlação entre } \\
\text { ansiedade } \\
\text { (STAl) e } \\
\text { síndrome de } \\
\text { Burnout (MBI) } \\
\text { foi testada a } \\
\text { partir da análise } \\
\text { de regressão } \\
\text { linear múltipla, } \\
\text { nível de } \\
\text { significância de } \\
5 \% \text {. }\end{array}$ & $\begin{array}{l}78 \\
\text { questionários: } \\
41 \quad \text { por } \\
\text { anestesistas for } \\
\text { mados }(21 \mathrm{~m} 20 \\
\text { f) e } 37 \text { por } \\
\text { residentes. }\end{array}$ & $\begin{array}{l}\text { A síndrome de Burnout apresentou } \\
\text { prevalência de } 2,43 \% \text { entre os } \\
\text { anestesiologistas e } 2,70 \% \text { entre médicos } \\
\text { residentes, enquanto alto risco para sua } \\
\text { manifestação nos anestesiologistas foi de } \\
21,95 \% \text { e para médicos residentes, de } \\
29,72 \% \text {. Existe associação entre ansiedade- } \\
\text { estado e as dimensões exaustão emocional } \\
\text { de Burnout, despersonalização } \\
\text { de Burnout e ansiedade (traço). A } \\
\text { ocorrência de ansiedade pode influenciar } \\
\text { negativamente a maneira como o indivíduo } \\
\text { enfrenta os fatores estressores cotidianos, o } \\
\text { que pode estar relacionado ao uso de } \\
\text { ineficazes estratégias de enfrentamento } \\
\text { diante do estresse. }\end{array}$ & $\begin{array}{l}\text { Entre suas limitações } \\
\text { estão a dificuldade para } \\
\text { investigar condições de } \\
\text { baixa prevalência e o } \\
\text { não estabelecimento de } \\
\text { causalidade. Outra } \\
\text { limitação do presente } \\
\text { estudo é o uso de } \\
\text { amostra } \\
\text { conveniência, o que } \\
\text { limita o poder de } \\
\text { generalização e de } \\
\text { inferência a partir dos } \\
\text { achados. }\end{array}$ \\
\hline
\end{tabular}




\begin{tabular}{|c|c|c|c|c|c|c|}
\hline $\begin{array}{c}\text { Autor } \\
\text { principal }\end{array}$ & $\begin{array}{c}\text { Ano de } \\
\text { publicação }\end{array}$ & País & $\begin{array}{l}\text { Questionário/ } \\
\text { método } \\
\text { aplicado }\end{array}$ & $\begin{array}{c}\text { Público } \\
\text { analisado/ } \mathrm{n} \text { de } \\
\text { participantes }\end{array}$ & Conclusão sintética do artigo & Limitações de Estudo \\
\hline $\begin{array}{l}\text { Hyman et } \\
\text { al. [9] }\end{array}$ & 2017 & EUA & $\begin{array}{l}\text { MBI-HSS, NM } \\
\text { ASSIST, SF-12 } \\
\text { (adaptado) }\end{array}$ & $\begin{array}{l}\text { médicos } \\
\text { anestesiologista } \\
\text { s: } 201 \text {; } \\
\text { residentes } \\
\text { anestesistas: } 20\end{array}$ & $\begin{array}{l}\text { Constatou-se que as pessoas com maior } \\
\text { risco de Burnout são os mais jovens, alta } \\
\text { escolaridade, solteiros, com altas } \\
\text { expectativas e baixa autoestima. }\end{array}$ & $\begin{array}{l}\text { Como o Burnout tende } \\
\text { a afetar os mais jovens } \\
\text { e os residentes foram } \\
\text { sub-representados em } \\
\text { comparação com a } \\
\text { participação no ASA, o } \\
\text { risco real de Burnout } \\
\text { pode ser maior. }\end{array}$ \\
\hline $\begin{array}{l}\text { Yrondi et } \\
\text { al. [10] }\end{array}$ & 2017 & França & $\begin{array}{l}\text { Versão francesa } \\
\text { validada do MBI } \\
\text { enviada por e- } \\
\text { mail }\end{array}$ & $\begin{array}{l}271 \text { residentes: } \\
123 \text { residentes } \\
\text { de } \\
\text { anestesiologia e } \\
148 \text { residentes } \\
\text { psiquiátricos. }\end{array}$ & $\begin{array}{l}\text { Ambas as especialidades, pouco menos da } \\
\text { metade dos residentes apresentou sintomas } \\
\text { de Burnout, desta mais de } 10 \% \text { dos } \\
\text { participantes exibiram graus moderados a } \\
\text { altos de Burnout. }\end{array}$ & $\begin{array}{l}\text { Não há justificativa } \\
\text { clara sobre o } \\
\text { que motivou a escolha } \\
\text { das especialidades a } \\
\text { serem analisadas. }\end{array}$ \\
\hline $\begin{array}{l}\text { Sanfilipo F. e } \\
t \text { al [2] }\end{array}$ & 2017 & Itália & $\begin{array}{l}\text { Revisão } \\
\text { sistemática no } \\
\text { National Health } \\
\text { Service } \\
\text { (MEDLINE) }\end{array}$ & Não se aplica & $\begin{array}{l}\text { A prevalência de Burnout é alta dentre os } \\
\text { diversos níveis da carreira dos Aneste- } \\
\text { siologistas. Entretanto o pequeno número de } \\
\text { trabalhos e também a diferença de } \\
\text { metodologias, fazem necessário estudos } \\
\text { posteriores. }\end{array}$ & $\begin{array}{lr}\text { A principal limitação é } \\
\text { que os raversos } \\
\text { estudos apresentam, } \\
\text { faixas der corte } \\
\text { para Burnout e suas } \\
\text { esferas. Dessa forma } \\
\text { dificulta a análise dos } \\
\text { dados. }\end{array}$ \\
\hline $\begin{array}{l}\text { Ben Zid, A et } \\
\text { al. [11] }\end{array}$ & 2017 & Tunísia & $\begin{array}{l}3 \text { instrumentos } \\
\text { usados: } \\
\text { um questionário } \\
\text { em anônimo au- } \\
\text { to administrado, } \\
\text { MBI e ABDI a- } \\
\text { valiando a inten- } \\
\text { sidade da } \\
\text { depressão }\end{array}$ & $\begin{array}{l}149 \\
\text { participantes, m } \\
\text { édicos resi- } \\
\text { dentes de diver- } \\
\text { sas áreas, } 31 \\
\text { da área de } \\
\text { anestesiologia }\end{array}$ & 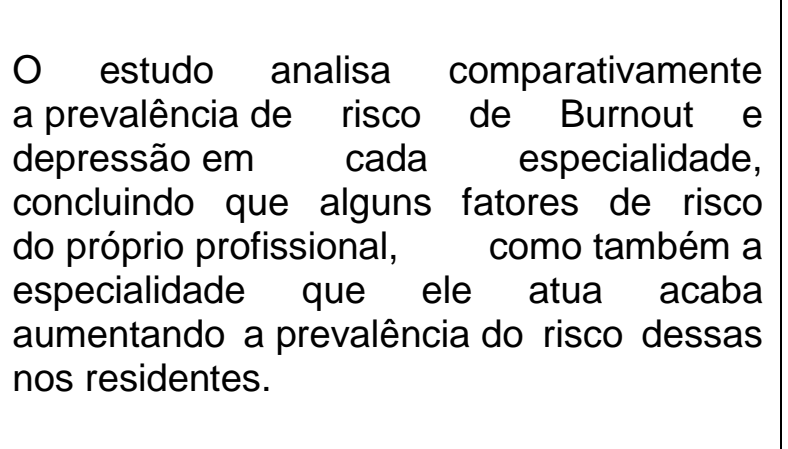 & $\begin{array}{l}\text { O estudo não é } \\
\text { apresentado na língua } \\
\text { inglesa (está em Turco). } \\
\text { Algumas popu- } \\
\text { lações de especialida- } \\
\text { des são representadas } \\
\text { por uma amostragem } \\
\text { baixa, podendo dar } \\
\text { um viés na } \\
\text { comparação. }\end{array}$ \\
\hline
\end{tabular}




\begin{tabular}{|c|c|c|c|c|c|c|}
\hline $\begin{array}{c}\text { Autor } \\
\text { principal }\end{array}$ & $\begin{array}{c}\text { Ano de } \\
\text { publicação }\end{array}$ & País & $\begin{array}{l}\text { Questionário/ } \\
\text { método } \\
\text { aplicado }\end{array}$ & $\begin{array}{c}\text { Público } \\
\text { analisado/ } \mathrm{n} \text { de } \\
\text { participantes }\end{array}$ & Conclusão sintética do artigo & Limitações de Estudo \\
\hline $\begin{array}{l}\text { Chakravarti, } \\
\text { A. et al. [12] }\end{array}$ & 2017 & Canadá & Não se aplica & Não se aplica & 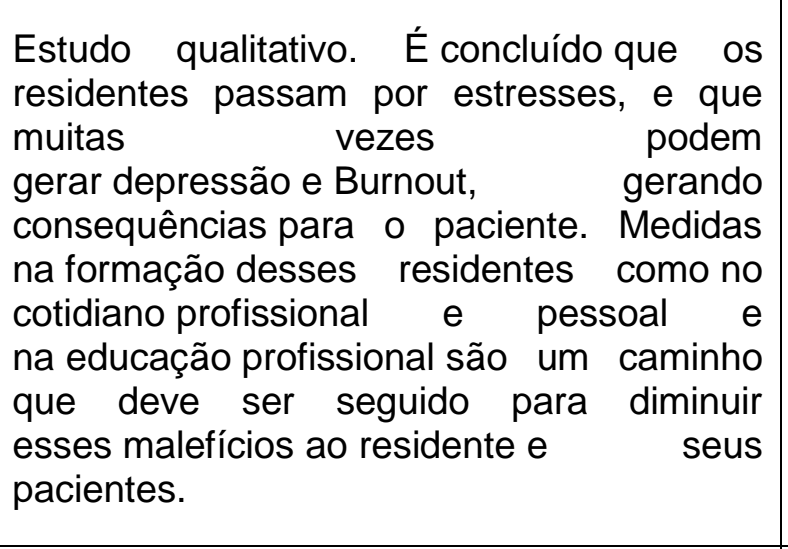 & $\begin{array}{l}\text { Apenas cita as } \\
\text { condições que os } \\
\text { residentes passam } \\
\text { (estresse, Burnout e } \\
\text { depressão) mas sem } \\
\text { uma análise do risco } \\
\text { por questionários e } \\
\text { testes por exemplo, } \\
\text { para comprovar que es } \\
\text { se grupo realmente te } \\
\text { m o risco de passar por } \\
\text { essas condições }\end{array}$ \\
\hline $\begin{array}{l}\text { Arayago et } \\
\text { al. [13] }\end{array}$ & 2016 & Venezuela & $\begin{array}{l}\text { MBI } \\
\text { espanhol }\end{array}$ & $\begin{array}{l}64 \text {, entre eles } 34 \\
\text { especialistas e } \\
30 \text { residentes }\end{array}$ & $\begin{array}{l}\text { Pesquisa descritiva transversal com } \\
\text { delineamento de campo em que se concluiu } \\
\text { que Burnout é prevalente em todos os três } \\
\text { quartos dos médicos entrevistados, sendo } \\
\text { que seis em cada dez eram mulheres e } \\
\text { pouco mais da metade eram médicos } \\
\text { residentes, demonstrando a necessidade de } \\
\text { melhorar as condições de trabalho do } \\
\text { serviço de anestesiologia. }\end{array}$ & $\begin{array}{l}\text { Amostra pequena em } \\
\text { apenas um hospital } \\
\text { regional venezuelano. }\end{array}$ \\
\hline $\begin{array}{l}\text { Turgut, } \\
\text { Namigar; et } \\
\text { al. [14] }\end{array}$ & 2016 & Turquia & $\begin{array}{l}\text { Aplicação } \\
\text { do MBI }\end{array}$ & 127 residentes & $\begin{array}{l}\text { Burnout é um problema muito comum na } \\
\text { residência. No estudo foi apresentada } \\
\text { diferença estatística entre a prevalência } \\
\text { de Burnout de acordo com os anos de } \\
\text { residência. }\end{array}$ & $\begin{array}{l}\text { Número limitado de } \\
\text { médicos residentes (de } \\
\text { apenas um hospital) e } \\
\text { de diversas áreas. }\end{array}$ \\
\hline
\end{tabular}




\begin{tabular}{|c|c|c|c|c|c|c|}
\hline $\begin{array}{c}\text { Autor } \\
\text { principal }\end{array}$ & $\begin{array}{c}\text { Ano de } \\
\text { publicação }\end{array}$ & País & $\begin{array}{l}\text { Questionário/ } \\
\text { método } \\
\text { aplicado }\end{array}$ & $\begin{array}{c}\text { Público } \\
\text { analisado/ } \mathrm{n} \text { de } \\
\text { participantes }\end{array}$ & Conclusão sintética do artigo & Limitações de Estudo \\
\hline $\begin{array}{l}\text { Wal, } \\
\text { Raymond } \\
\text { A.b. van Der } \\
\text { et al. [15] }\end{array}$ & 2016 & Alemanha & $\begin{array}{l}\text { Foi enviado } \\
\text { pesquisas } \\
\text { eletrônicas. }\end{array}$ & $\begin{array}{l}655 \text { residentes e } \\
\text { consultores } \\
\text { membros da } \\
\text { Sociedade de } \\
\text { Anestesia } \\
\text { Holandesa }\end{array}$ & $\begin{array}{l}\text { Residentes da área da anestesia, pelo seu } \\
\text { cotidiano, tem alto risco de } \\
\text { terem Burnout e malefícios psicológicos. } \\
\text { Nesse estudo foi demonstrado que aspectos } \\
\text { pessoais acabam atuando como fatores de } \\
\text { risco e aumentando a chance } \\
\text { dessas condições aparecerem nessa } \\
\text { população. }\end{array}$ & $\begin{array}{l}\text { Adesão à pesquisa foi } \\
33,5 \% \text {, uma taxa menor } \\
\text { quando comparado } \\
\text { com os outros } \\
\text { trabalhos. }\end{array}$ \\
\hline $\begin{array}{l}\text { Oliveira, } \\
\text { Gildasio S. } \\
\text { de et al. [16] }\end{array}$ & 2015 & EUA & $\begin{array}{l}\text { Questionário de } \\
\text { própria autoria } \\
\text { criado por uma } \\
\text { base de dados, } \\
\text { utilizando Postg } \\
\text { reSQL, compost } \\
\text { a por } 9 \\
\text { questões }\end{array}$ & $\begin{array}{c}1500 \text { residentes } \\
\text { anestesiologista } \\
\text { da Sociedade } \\
\text { Americana de } \\
\text { Anestesiologista } \\
\text { foram } \\
\text { selecionados } \\
\text { aleatoriamente } \\
\text { para serem } \\
\text { participantes. }\end{array}$ & $\begin{array}{l}\text { Resultados mostram que os } 9 \text { itens de } \\
\text { Oliveira Filho et al. da escala de supervisão } \\
\text { podem ser aplicadas para avaliação geral } \\
\text { (departamento, rotação) dos programas de } \\
\text { treinamento em anestesia. Não se sabe o } \\
\text { quanto as pontuações de supervisão do } \\
\text { anestesista individual da faculdade podem } \\
\text { melhorar ou influenciar erros médicos. }\end{array}$ & $\begin{array}{l}\text { As pesquisas foram } \\
\text { autorreferidas e podem } \\
\text { não representar } \\
\text { comportamentos reais. } \\
\text { O viés de resposta é } \\
\text { sempre r uma } \\
\text { preocupação r em } \\
\text { estudos transversais } \\
\text { com questionários. }\end{array}$ \\
\hline $\begin{array}{l}\text { Vinson, Amy } \\
\text { E.; Mitchell, } \\
\text { John D [17] }\end{array}$ & 2014 & EUA & $\begin{array}{l}\text { Dois } \\
\text { questionários } \\
\text { online de própria } \\
\text { autoria (1 } 1^{\underline{a}} \text { parte } \\
\text { da pesquisa }- \\
\text { Parte } \quad \text { A } \\
\text { destinada aos } \\
\text { diretores } \\
\text { de residência e } \\
2^{\text {a }} \text { parte - Parte } \\
\text { B, destinado aos } \\
\text { residentes) }\end{array}$ & $\begin{array}{l}64 \quad \text { Diretores } \\
\text { de residência } \\
\text { de anestesiolo- } \\
\text { gia; } 186 \\
\text { Residentes } \\
\text { de anestesiolo- } \\
\text { gia }\end{array}$ & $\begin{array}{l}\text { Pesquisa descritiva a respeito do } \\
\text { conhecimento sobre a prevalência e } \\
\text { natureza das estruturas de suporte aos } \\
\text { residentes de anestesia no local de atuação } \\
\text { por parte dos diretores de programas } \\
\text { de residência de anestesiologia e pelos } \\
\text { próprios residentes, que demonstraram } \\
\text { conhecer os recursos, mas apesar de } \\
\text { afirmarem da disponibilidade dos programas } \\
\text { e recursos, houve uma grande discrepância } \\
\text { entre os programas que o diretor do } \\
\text { programa afirmou ter e o que os residentes } \\
\text { acharam que estava disponível. }\end{array}$ & $\begin{array}{lr}\text { Apesar do } & \text { grande } \\
\text { número inicial } & \text { de } \\
\text { instituições de residên- } \\
\text { cia de anestesiologia } \\
\text { convidadas a participar } \\
\text { da pesquisa inicial, } \\
\text { houve um número } \\
\text { reduzido de residentes } \\
\text { participantes } \\
\text { segunda parte da } \\
\text { pesquisa, o que pode } \\
\text { apresentar } \\
\text { resultado um } \\
\text { representado }\end{array}$ \\
\hline
\end{tabular}




\begin{tabular}{|c|c|c|c|c|c|c|}
\hline $\begin{array}{c}\text { Autor } \\
\text { principal }\end{array}$ & $\begin{array}{c}\text { Ano de } \\
\text { publicação }\end{array}$ & País & $\begin{array}{l}\text { Questionário/ } \\
\text { método } \\
\text { aplicado }\end{array}$ & $\begin{array}{c}\text { Público } \\
\text { analisado/ } \mathbf{n} \text { de } \\
\text { participantes }\end{array}$ & Conclusão sintética do artigo & Limitações de Estudo \\
\hline $\begin{array}{l}\text { Eisenach, } \\
\text { John H. et al. } \\
\text { [18] }\end{array}$ & 2014 & EUA & $\begin{array}{l}\text { Minnesota Leisu } \\
\text { re- } \\
\text { Time Physical } \\
\text { Activity Questio- } \\
\text { nnaire, Cohen's } \\
\text { Perceived Stres } \\
\text { s Scale,Spielber } \\
\text { ger State Anxiet } \\
\text { y Index } \\
\text { e Resiliency and } \\
\text { Daily Well- } \\
\text { being Surveys }\end{array}$ & $\begin{array}{l}18 \text { residentes } \\
\text { clínico- } \\
\text { anestesistas } \\
\text { com } 1 \text { ano de } \\
\text { formados no } \\
\text { momento do } \\
\text { recrutamento }\end{array}$ & $\begin{array}{l}\text { Coorte prospectiva em que se constatou que } \\
\text { no início do treinamento, os residentes de } \\
\text { anestesia provavelmente perceberam um } \\
\text { baixo grau de liberdade em um cenário de } \\
\text { altas expectativas ou demanda. Ademais, os } \\
\text { residentes encontravam-se particularmente } \\
\text { otimistas sobre o início da formação no seu } \\
\text { campo de escolha e creditavam o início da } \\
\text { anestesiologia ser um estressor instigante. } \\
\text { Natureza delicada de estudar recém- } \\
\text { formados residentes dentro dos limites } \\
\text { éticos de confidencialidade limitou o número } \\
\text { de participantes. }\end{array}$ & $\begin{array}{l}\text { Há potencial de viés de } \\
\text { seleção, como o grau } \\
\text { de resiliência nos } \\
\text { participantes pode ser } \\
\text { tal que muitas das } \\
\text { variáveis psicológicas e } \\
\text { fisiológicas exploradas } \\
\text { não foram afetadas pelo } \\
\text { estresse de começar a } \\
\text { residência, mas podem } \\
\text { ser afetadas em uma } \\
\text { população mais ampla. }\end{array}$ \\
\hline $\begin{array}{l}\text { Moura, } P \text {. } \\
\text { Alves de. [19] }\end{array}$ & 2014 & Portugal & $\begin{array}{l}\text { Questionário Psi } \\
\text { cosocial de } \\
\text { Copenhagen } \\
\text { versão } 2 \\
\text { adaptado para a } \\
\text { população } \\
\text { portuguesa }\end{array}$ & $\begin{array}{l}\text { residentes de } \\
\text { psiquiatria: } 19 \mathrm{E} \\
\text { de } \\
\text { anestesiologia: } \\
20\end{array}$ & $\begin{array}{l}\text { Os residentes de anestesiologia do estudo } \\
\text { eram relativamente jovens e a maioria é do } \\
\text { sexo feminino, sendo essa população mais } \\
\text { afetada pela depressão e síndrome } \\
\text { de Burnout de acordo com a "influência do } \\
\text { trabalho" na vida pessoal, enquanto que } \\
\text { para os indivíduos do sexo masculino, as } \\
\text { "demandas quantitativas" é que geram } \\
\text { maiores dificuldades. }\end{array}$ & $\begin{array}{l}\text { Os autores afirmaram } \\
\text { que a pesquisa tem a } \\
\text { limitação de ter } \\
\text { um número restrito de } \\
\text { participantes e estar } \\
\text { associado a apenas } \\
\text { uma instituição, logo } \\
\text { não é possível } \\
\text { generalizar }\end{array}$ \\
\hline $\begin{array}{l}\text { Lapa, Teresa } \\
\text { A. et al. [20] }\end{array}$ & 2014 & Portugal & $\begin{array}{l}\text { Foi aplicado o } \\
\text { Questionário } \\
\text { SQA criado } \\
\text { pelos próprios } \\
\text { pesquisadores }\end{array}$ & $\begin{array}{l}710 \\
\text { profissionais: } \\
\text { englobado } \\
\text { especialistas em } \\
\text { anestesiologia } \\
\text { e residentes de } \\
\text { anestesiologia }\end{array}$ & $\begin{array}{l}\text { SQA é uma boa medida de mensurar fatores } \\
\text { estressantes em médicos anestesistas. } \\
\text { Resultados demonstram que o SQA é um } \\
\text { instrumento robusto e confiável. }\end{array}$ & $\begin{array}{l}\text { O atual formato não } \\
\text { permite estabelecer cor } \\
\text { relações entre variáveis } \\
\text { diferentes, além do } \\
\text { questionário estar em } \\
\text { português. }\end{array}$ \\
\hline
\end{tabular}




\begin{tabular}{|c|c|c|c|c|c|c|}
\hline $\begin{array}{c}\text { Autor } \\
\text { principal }\end{array}$ & $\begin{array}{c}\text { Ano de } \\
\text { publicação }\end{array}$ & País & $\begin{array}{l}\text { Questionário/ } \\
\text { método } \\
\text { aplicado }\end{array}$ & $\begin{array}{c}\text { Público } \\
\text { analisado/ } \mathrm{n} \text { de } \\
\text { participantes }\end{array}$ & Conclusão sintética do artigo & Limitações de Estudo \\
\hline $\begin{array}{l}\text { Walsh, } \\
\text { Abigail M. } \\
\text { [21] }\end{array}$ & 2014 & Irlanda & \begin{tabular}{lr}
\multicolumn{2}{l}{ Questionário } \\
criado & pelos \\
autores & que \\
analisam & $\mathrm{o}$ \\
cotidiano & \\
profissional & $\mathrm{e}$ \\
pessoal & dos \\
residentes & \\
\end{tabular} & $\begin{array}{l}39 \text { residentes de } \\
\text { anestesiologia. }\end{array}$ & $\begin{array}{l}\text { O cotidiano estressante e excesso de } \\
\text { trabalho em horas acaba gerando } \\
\text { uma influência negativa na qualidade do } \\
\text { trabalho. }\end{array}$ & $\begin{array}{lr}\text { Não é dito como foi feito } \\
\text { o questionário de forma } \\
\text { detalhada e há } \\
\text { uma adesão de } & 55 \% \\
\text { da população a } & \text { ser } \\
\text { questionada. } & \end{array}$ \\
\hline $\begin{array}{l}\text { Shams, } \\
\text { Terek. [22] }\end{array}$ & 2013 & Egito & $\begin{array}{l}\text { Estudo de } \\
\text { corte transversal } \\
\text { que utilizou } \\
\text { como } \\
\text { questionário o } \\
\text { MBI e o } \\
\text { American Insti- } \\
\text { tute of Stress, } \\
\text { para mensurar } \\
\text { Estresse } \\
\text { e Burnout no } \\
\text { Hospital } \\
\text { universitário } \\
\text { de Mansoura }\end{array}$ & $\begin{array}{l}98 \text { profissionais } \\
\text { de } \\
\text { anestesiologia } \\
\text { com carreira } \\
\text { acadêmica }\end{array}$ & $\begin{array}{l}\text { Estresse e Burnout foram causados nos } \\
\text { Anestesiologistas devido a falta de apoio no } \\
\text { trabalho, isso foi especialmente verdade nos } \\
\text { residentes e nos professores auxiliares. } \\
\text { Os autores concluíram que uma estratégia } \\
\text { bem organizada para mitigar a pesada } \\
\text { demanda profissional de anestesiologistas } \\
\text { em nível acadêmico aliviaria o estresse e } \\
\text { o Burnout. }\end{array}$ & $\begin{array}{l}\text { Mesmo com o uso de } \\
\text { medidas validadas o } \\
\text { estudo pode não ter } \\
\text { captado de maneira } \\
\text { completa e precisa } \\
\text { cada sentimento dos } \\
\text { anestesiologistas. O } \\
\text { estudo de corte } \\
\text { transversal pode ter } \\
\text { criado dificuldades em } \\
\text { averiguar } \\
\text { casualidade. Adicional- } \\
\text { mente o estudo foi feito } \\
\text { com anestesiologistas } \\
\text { com carreira } \\
\text { acadêmica, ou seja, o } \\
\text { resultado pode não } \\
\text { ser aplicado a todos os } \\
\text { anestesiologistas. }\end{array}$ \\
\hline
\end{tabular}




\begin{tabular}{|c|c|c|c|c|c|c|}
\hline $\begin{array}{c}\text { Autor } \\
\text { principal }\end{array}$ & $\begin{array}{c}\text { Ano de } \\
\text { publicação }\end{array}$ & País & $\begin{array}{l}\text { Questionário/ } \\
\text { método } \\
\text { aplicado }\end{array}$ & $\begin{array}{c}\text { Público } \\
\text { analisado/ } \mathbf{n} \text { de } \\
\text { participantes }\end{array}$ & Conclusão sintética do artigo & Limitações de Estudo \\
\hline $\begin{array}{l}\text { Oliveira, } \\
\text { Gildasio S. } \\
\text { de et al. [23] }\end{array}$ & 2013 & EUA & $\begin{array}{l}\text { Questionário di- } \\
\text { vidido em } 5 \\
\text { partes: fatores } \\
\text { demográficos, } \\
\text { MBI, } \\
\text { Harvard depres- } \\
\text { sionscale, } 10 \\
\text { questões proje- } \\
\text { tadas para } \\
\text { avaliar a melhor } \\
\text { prática de } \\
\text { anestesiologia, } \\
\text { e } 7 \text { questões: } \\
\text { avaliar erros } \\
\text { auto-relatados. }\end{array}$ & $\begin{array}{l}1508 \text { residentes } \\
\text { de anestesiologi } \\
\text { a }\end{array}$ & $\begin{array}{l}\text { Burnout, depressão e pensamentos suicidas } \\
\text { são muito prevalentes em residentes de } \\
\text { anestesiologia. Os estudos e } \\
\text { suas correlações demonstram que além dos } \\
\text { efeitos sobre a saúde dos estagiários de } \\
\text { anestesiologia, o Burnout e a depressão } \\
\text { também podem afetar o cuidado e a } \\
\text { segurança do paciente. }\end{array}$ & $\begin{array}{lr}\text { As pesquisas } & \text { foram } \\
\text { autorreferidas. } & \text { Um } \\
\text { grupo de características } \\
\text { demográficas, sociais e } \\
\text { relacionadas r ao } \\
\text { trabalho foram } \\
\text { coletadas em estudos } \\
\text { anteriores, O estudo } \\
\text { não avaliou a a } \\
\text { frequência de erros } \\
\text { cometidos pelos } \\
\text { entrevistados, mas sim } \\
\text { suas respostas, } \\
\text { conforme declarado. Os } \\
\text { questionários não foram } \\
\text { concluídos em um } \\
\text { ambiente controlado. }\end{array}$ \\
\hline $\begin{array}{l}\text { Arenson- } \\
\text { pandikow e } \\
\text { Mendes [24] }\end{array}$ & 2013 & Brasil & Não se aplica & Não se aplica & $\begin{array}{l}\text { Estudo qualitativo. O segundo ano de } \\
\text { treinamento em anestesiologia apresentou } \\
\text { os maiores índices de estresse ocupacional } \\
\text { em relação aos outros níveis de formação e } \\
\text { a seus preceptores; os níveis foram mais } \\
\text { elevados no gênero feminino; a faixa etária } \\
\text { de maior nível de estresse ocupacional foi a } \\
\text { entre } 25 \text { e } 35 \text { anos; o menor nível de } \\
\text { estresse foi evidenciado no grupo de } \\
\text { casados em relação a solteiros e } \\
\text { divorciados. ocupacional e o alcoolismo } \\
\text { mostrou-se altamente prevalente nos } \\
\text { residentes. }\end{array}$ & $\begin{array}{l}\text { Conclusões foram } \\
\text { expostas } \\
\text { apresentar dados que } \\
\text { as comprovassem. }\end{array}$ \\
\hline
\end{tabular}

Legenda: STAI (State Trait Anxiety Inventory); MBI (Maslach Burnout Inventory); ABDI (Abstract Beck Depressi-on Inventory); SQA

(Stress Questionnaire in Anaes-thesiologists), 


\section{DISCUSSÃO}

O estresse é parte do cotidiano de todo médico, no entanto, há áreas em que a necessidade de convívio com tal fator é maior se comparado a outras [18]. Diversos estudos analisaram as áreas da medicina que são mais estressantes, e os artigos listados nesta revisão sistemática foram enfáticos nas comparações: 9 (nove) artigos realizaram estudos para descrever as áreas mais estressantes e o possível risco do desenvolvimento do Burnout, e o resultado dos artigos foram semelhantes em citar a Anestesiologia como área médica mais estressante e um dos principais motivos foram as instabilidades da homeostasia dos pacientes durante os procedimentos cirúrgicos, vias aéreas difíceis e outras emergências que possam ocorrer repentinamente. [2, 8-11, 18, 19, 22 , 24]

Desse modo, aliado ao teor estressante da carreira e com a rotina de trabalho que muitas vezes o profissional anestesiologista frequenta diariamente, há grande índice dos profissionais que afirmam sofrer alto desgaste emocional, alta despersonalização e baixa conquista pessoal (fatores clássicos da descrição do Burnout) de modo a confirmar a afirmação de que a anestesiologia é uma área com grande propensão de Burnout, fato também demonstrado por essa coletânea. [2, 8-10, 15, 19, 24]

Entretanto, muitos outros artigos mencionaram que o Burnout está difundido nas diferentes áreas médicas, apesar de a anestesiologia apresentar os maiores números de indivíduos com essa síndrome. Através de diversas análises dos estudos, pode-se perceber que o Burnout se desenvolve justamente em médicos recém formados, principalmente nos residentes [2, 8-16, 18$21,24]$ sobretudo nos mais jovens em idade [2, 9, 14, 24, 19] e com alguns autores afirmando sobre o predomínio do Burnout no sexo feminino $[2,19]$ enquanto que outros contestam a relação do sexo e que os números são maiores se comparados ao sexo masculino pela maior participação das mulheres nas pesquisas. [13, 23, 24] Portanto, seguindo o proposto, os principais afetados pelo Burnout são os residentes mais jovens da área da anestesiologia.

Tal relação pode ser afirmada pois o jovem recém-formado se depara com uma rotina a qual não estava adaptado e não possui uma estrutura psicossocial suficiente para enfrentar a nova condição na qual se encontra $[2,9,14,24,19]$. São muitas responsabilidades; dificuldades nos procedimentos a qual ainda não está completamente apto ou seguro a realizar; muitos horários de estágio a cumprir, como também muitos relatórios para desenvolver e se manter atualizado no estudo e em congressos; pouco convívio familiar; poucas horas de sono; má alimentação; assim como a falta do suporte no trabalho, principalmente quando a atividade pode desenvolver consequências ao paciente (Tabela 1). Alguns estudos listaram alguns fatores que poderiam ser protetores ao residente quanto ao desenvolvimento de Burnout, como ter filhos, ser casado, todavia em outros demonstrava que tal relação não era significativa. [2, 8-11, 14, 15, 19-24] 
TABELA 1 - Fatores pré disponentes à S. de Burnout

\begin{tabular}{l}
\hline Muitas responsabilidades \\
\hline Dificuldade nos procedimentos \\
\hline falta de suporte no trabalho \\
\hline Alta carga horária \\
\hline grande volume de relatórios para desenvolver \\
\hline se manter atualizado em estudos e congressos \\
\hline pouco convívio familiar \\
\hline poucas horas de sono \\
\hline má alimentação \\
\hline
\end{tabular}

O estudo de Moura (2014) [19] apontou que o sexo feminino tem maior propensão a desenvolver o Burnout devido a "influência do trabalho" na vida pessoal gerando conflitos familiares, sendo apoiado pelo estudo de Heinke et. al apud Moura (2014) envolvendo 3541 residentes de anestesiologia, enquanto que outros estudos não demonstraram ser esse um fator de risco para o desenvolvimento do Burnout. Portanto, necessita ainda de maiores estudos - com maior número de participantes - para verificar a questão de prevalência de Burnout nos sexos e os principais motivos.

Um dos questionamentos de um dos estudos foi se a Síndrome do Burnout era resultado de erros médicos ou se era uma das consequências. Com a análise dos estudos [7, 8, 10, 16-18, 21, 23] pode-se determinar que a falta de uma adequada orientação nos primeiros anos da carreira médica, como nos residentes da anestesiologia, podem gerar muitas consequências aos pacientes, gerando o sentimento de culpa no profissional, que tem maior risco de desenvolver o Burnout em curto prazo ou ao longo do tempo caso não consiga lidar com a aprendizagem ou com futuros erros. Apesar disso, ainda deve-se considerar significativo que o indivíduo com Burnout tem propensão a erros médicos em comparação a profissionais sem a síndrome.

Em diversos estudos [8-11, 13-15, 23, 24] foi utilizado o Maslach Burnout Inventory-Human Services Survey (MBI-HSS), que continua sendo o padrão ouro para a pesquisa do Burnout em profissionais da saúde, pois com o somatório de cada dimensão (exaustão emocional, realização profissional e despersonalização) pode-se avaliar se o indivíduo tem ou não a síndrome e o grau de acometimento em casos afirmativos. O questionário internacionalmente reconhecido consiste de 22 questões, das quais 9 avaliam a Exaustão emocional (EE - o quanto o indivíduo fica estressado e psicologicamente esgotado afetando a capacidade pessoal de responder às necessidades de um paciente), 5 avaliam a despersonalização (DP - situação em que o médico tem uma abordagem clínica e desumana para com o paciente) e 8 avaliam a Realização pessoal (PA - sentimento pessoal referente ao valor do trabalho ao indivíduo), as quais recebem pontuação na escala de Likert de 7 pontos (codificada a partir de 0-6) a partir das respostas dos participantes. Tais estudos demonstraram que os residentes de anestesiologia eram os que mais pontuavam (principalmente em "Despersonalização") se comparado aos anestesistas experientes. 
Outros estudos utilizaram o MBI-HSS associado a outro questionário, seja questionário adaptado ou de própria autoria [11, 15, 22]; outros utilizaram questionários adaptados para o país onde seria realizado a pesquisa [18, 19, 23] e outros ainda utilizaram questionários de própria autoria (questionário próprio) $[7,16,17,20,21]$ para avaliar o grau de estresse e Burnout nos profissionais, todavia, tais questionários necessitam de novas aplicações criteriosas para avaliar o grau de significância dos mesmos e se podem retratar a realidade, assim como o grau de aplicabilidade se comparado ao MBI-HSS.

Alguns dos questionários utilizados tinham como objetivo avaliar a relação entre Burnout e o uso de outras substâncias pelos profissionais [9, 11, 14, 24] no entanto os próprios autores afirmaram que há questionamentos da veracidade das informações, visto que muitos participantes podem não ter respondido tal pesquisa específica de uso de substâncias com acanhamento de relatar sua realidade. Dessas pesquisas, a maioria resultou que não há associação entre Burnout e uso de outras substancias e de álcool, todavia, houve estudos que demonstrou maior consumo de bebidas alcoólicas em residentes.

Muitos dos artigos selecionados relataram a necessidade de um suporte adequado na própria instituição de atuação como apoio para o profissional de modo a prevenir a síndrome de Burnout ou para o auxiliar na recuperação [2, 8, 12, 17, 19, 24]. Dentre as propostas estão: maior acompanhamento do preceptor para com o residente de modo a orientar adequadamente nos procedimentos auxiliando nas dúvidas e dificuldades; reuniões mensais entre os residentes para discussão desse fator que cada vez mais tem afetado a classe médica, principalmente os recémformados; padronizar as horas de estágio evitando longas jornadas por semana; criação de programa de treinamento dedicado à resiliência e habilidades de enfrentamento; otimizar um ambiente respeitoso de trabalho; além do incentivo aos residentes a frequentarem tais grupos de apoio (Tabela 2).

TABELA 2 - Propostas para profilaxia ou recuperação do indivíduo com S. de Burnout

\begin{tabular}{l}
\hline Acompanhamento adequado do preceptor ao residente \\
\hline Orientação quanto aos diversos procedimentos \\
\hline Reuniões mensais entre os residentes para discussão das dificuldades no serviço \\
\hline Difundir o debate sobre o tema Burnout na classe médica \\
\hline padronizar as horas de estágio evitando lonjas jornadas semanais \\
\hline Criação de programas de treinamento profissional e habilidades de enfrentamento \\
\hline Otimizar o ambiente de trabalho, de modo a ser respeitoso e incentivador \\
\hline Incentivar os residentes a frequentarem os grupos de apoio contra a S. de Burnout \\
\hline
\end{tabular}

Apenas 5 (cinco) estudos foram realizados com público específico de residentes de anestesiologia $[7,14,17,23,24]$ e que confirmaram alguns dos apontamentos descritos neste trabalho. Entretanto, mesmo com a presente pesquisa, ainda não pode-se afirmar com excelência o grau de acometimento dos residentes de anestesiologia quanto ao Burnout e as principais características 
da síndrome nesse público, visto que o número de participantes das pesquisas eram em números limitados e inferiores se comparado a real população de residentes. Também ficou evidente a necessidade de maiores pesquisas com os residentes de anestesiologia brasileiros, visto que a maior parte das pesquisas aqui relatadas são estrangeiras e que podem não representar o cenário nacional, principalmente com a constante mudança da medicina e do mercado de trabalho.

\section{CONCLUSÃO}

Visto que a anestesiologia foi apontada nos estudos como uma das áreas médicas mais estressantes e além disso, uma outra afirmativa presente em outro estudos de que médicos recémformados estão mais susceptíveis ao estresse entende-se que os residentes de anestesiologia estão propensos a desenvolveram a síndrome do Burnout por diversos fatores de risco diretamente relacionadas com suas atividades diárias, e apesar de existir meios para lidar com essa problemática, os artigos apontaram que existe uma deficiência em mecanismos de apoio de modo a prevenir e potencializar a recuperação. Criando assim, um cenário preocupante para o médico anestesiologista, principalmente para o residente.

Após a revisão sistemática e análise dos estudos encontrados, apenas 5 deles relacionam-se diretamente com o público restrito "residentes de anestesiologia" e além disso o número de participantes foi restrito, dessa forma mesmo após a revisão não podemos afirmar o quanto a síndrome de Burnout acomete o público analisado. Além disso, poucos estudos são nacionais dessa maneira não podemos categoricamente afirmar que a realidade dos outros países se reflita no Brasil, necessitando assim de mais estudos na área.

\section{REFERÊNCIAS}

[1] Rama-Maceiras, Pablo; Jokinen, Johanna; Kranke, Peter. Stress and Burnout in anaesthesia. Current Opinion In Anaesthesiology, [s.I.], v. 28, n. 2, p.151-158, abr. 2015. Ovid Technologies (Wolters Kluwer Health). http://dx.doi.org/10.1097/aco.0000000000000169.

[2] Filippo Sanfilippo, Alberto Noto, Grazia Foresta, et al., "Incidence and Factors Associated with Burnout in Anesthesiology: A Systematic Review," BioMed Research International, vol. 2017, Article ID 8648925, 10 pages, 2017. https://doi.org/10.1155/2017/8648925.

[3] Gracino Mariana Evangelista, Zitta Ana Laura Lima, Mangili Otavio Celeste, Massuda Ely Mitie. A saúde física e mental do profissional médico: uma revisão sistemática. Saúde debate [Internet]. 2016 Sep [cited 2018 July 28] ; 40( 110 ): 244-263. Available from: http://www.scielo.br/scielo.php?script=sci_arttext\&pid=S0103$11042016000300244 \&$ Ing=en. http://dx.doi.org/10.1590/0103-1104201611019.

[4] Moreira, Hyan De Alvarenga; Souza, Karen Nattana De; Yamaguchi, Mirian Ueda. Síndrome de Burnout em médicos: uma revisão sistemática. Revista Brasileira de Saúde Ocupacional, [s.I.], 
v. 43, p.43-54, 12 mar. 2018. FapUNIFESP (SciELO). http://dx.doi.org/10.1590/23176369000013316.

[5] Moher D, Liberati A, Tetzlaff J, Altman DG, The PRISMA Group (2009). Preferred Reporting Items for Systematic Reviews and Meta-Analyses: The PRISMA Statement. PLoS Med 6(7): e1000097. doi:10.1371/journal.pmed1000097

[6] Liberati A, Altman DG, Tetzlaff J, Mulrow C, Gøtzsche PC, loannidis JPA, et al. The PRISMA statement for reporting systematic reviews and meta-analyses of studies that evaluate healthcare interventions: explanation and elaboration. BMJ. 2009;339:b2700. PubMed PMID: 19622552.

[7] Benzor, Hubert A. et al. Pediatric Anesthesiology Fellows' Perception of Quality of Attending Supervision and Medical Errors. Anesthesia \& Analgesia, [s.I.], v. 126, n. 2, p.639-643, fev. 2018. Ovid Technologies (Wolters Kluwer Health). http://dx.doi.org/10.1213/ane.0000000000002445.

[8] Govêia, Catia Sousa et al. Associação entre síndrome de Burnout e ansiedade em residentes e anestesiologistas do Distrito Federal. Brazilian Journal Of Anesthesiology, [s.I.], v. 68, n. 5, p.442-446, set. 2018. Elsevier BV. http://dx.doi.org/10.1016/j.bjan.2018.02.007.

[9] Hyman, Steve Alan et al. A Survey Evaluating Burnout, Health Status, Depression, Reported Alcohol and Substance Use, and Social Support of Anesthesiologists. Anesthesia \& Analgesia, [s.I.], v. 125, n. 6, p.2009-2018, dez. 2017. Ovid Technologies (Wolters Kluwer Health). http://dx.doi.org/10.1213/ane.0000000000002298.

[10] Yrondi, Antoine et al. Burnout compared between anaesthesiology and psychiatry residents in France. European Journal Of Anaesthesiology, [s.I.], v. 34, n. 7, p.480-482, jul. 2017. Ovid Technologies (Wolters Kluwer Health). http://dx.doi.org/10.1097/eja.0000000000000573

[11] Zid, A. Ben et al. Burnout chez les résidents en médecine tunisiens: à propos de 149 cas. L'encéphale, [s.I.], v. [], n. [], p.1-1, set. 2017. Elsevier BV.

http://dx.doi.org/10.1016/j.encep.2017.06.006.

[12] Chakravarti, Anita et al. Anesthesiology Resident Wellness Program at the University of Saskatchewan: curriculum content and delivery. Canadian Journal Of Anesthesia/journal Canadien D'anesthésie, [s.I.], v. 64, n. 2, p.199-210, 14 nov. 2016. Springer Nature. http://dx.doi.org/10.1007/s12630-016-0773-0.

[13] Arayago Robelsy, González Álvaro, Limongi María, Guevara Harold. Síndrome de Burnout en residentes y especialistas de anestesiología. Salus [Internet]. 2016 Abr [citado 2018 Ago 08] ; 20 ( 1 ): 13-21. Disponible en: http://www.scielo.org.ve/scielo.php?script=sci_arttext\&pid=S131671382016000100004\&lng=es. ISSN 1316-7138.

[14] Turgut, Namigar et al. Burnout Syndrome During Residency. Turkish Journal Of Anesthesia And Reanimation, [s.I.], v. 44, n. 5, p.258-264, 16 nov. 2016. AVES Publishing Co.. http://dx.doi.org/10.5152/tjar.2016.28000.

[15] Wal, Raymond A.b. van Der et al. Psychological distress, Burnout and personality traits in Dutch anaesthesiologists. European Journal Of Anaesthesiology, [s.I.], v. 33, n. 3, p.179-186, mar. 2016. Ovid Technologies (Wolters Kluwer Health). http://dx.doi.org/10.1097/eja.0000000000000375.

[16] Oliveira, Gildasio S. de et al. Reliability and Validity of Assessing Subspecialty Level of Faculty Anesthesiologists' Supervision of Anesthesiology Residents. Anesthesia \& Analgesia, [s.I.], v. 120, n. 1, p.209-213, jan. 2015. Ovid Technologies (Wolters Kluwer Health). http://dx.doi.org/10.1213/ane.0000000000000453. 
[17] Vinson, Amy E.; Mitchell, John D.. Assessing levels of support for residents following adverse outcomes: A national survey of anesthesia residency programs in the United States. Medical Teacher, [s.I.], v. 36, n. 10, p.858-866, 7 maio 2014. Informa UK Limited. http://dx.doi.org/10.3109/0142159x.2014.910299.

[18] Eisenach, John H. et al. The Psychological and Physiological Effects of Acute Occupational Stress in New Anesthesiology Residents. Anesthesiology, [s.I.], v. 121, n. 4, p.878-893, out. 2014. Ovid Technologies (Wolters Kluwer Health).

http://dx.doi.org/10.1097/aln.0000000000000397.

[19] Moura, P. Alves de. Psychosocial risks in Psychiatry and Anaesthesiology residents in a Portuguese General and University Hospital. La Medicina del Lavoro, Milão, v. 2, n. 107, p.129140, abr. 2016. PMID: 27015028.

[20] Lapa, Teresa A. et al. Stressors in anaesthesiology. European Journal Of Anaesthesiology, [s.I.], v. 33, n. 11, p.807-815, nov. 2016. Ovid Technologies (Wolters Kluwer Health). http://dx.doi.org/10.1097/eja.0000000000000518.

[21] Walsh, Abigail M.; McCarthy, Denise; Ghori, Kamran. Anesthesiology Resident Burnout-An Irish Perspective. Anesthesia \& Analgesia, [s.I.], v. 118, n. 2, p.482-483, fev. 2014. Ovid Technologies (Wolters Kluwer Health). http://dx.doi.org/10.1213/ane.0000000000000037.

[22] Shams, Terek. Job Stress and Burnout among Academic Career Anaesthesiologists at an Egyptian University Hospital. Sultan Qaboos University Medical Jornal. Muscat, p. 287-295. maio 2013. PMID: 23862036

[23] Oliveira, Gildasio S. de et al. The Prevalence of Burnout and Depression and Their Association with Adherence to Safety and Practice Standards. Anesthesia \& Analgesia, [s.I.], v. 117, n. 1, p.182-193, jul. 2013. Ovid Technologies (Wolters Kluwer Health). http://dx.doi.org/10.1213/ane.0b013e3182917da9.

[24] Arenson-Pandikow, Helena Maria; Mendes, Florentino Fernandes. Residentes de anestesiologia: importância do bem-estar ocupacional. In: GASTÃO F. DUVAL NETO (Brasília). Sociedade Brasileira de Anestesiologia (Ed.). Bem-estar ocupacional em anestesiologia. Brasília: Conselho Federal de Medicina, 2013. p. 201-225. Disponível em: $<$ https://portal.cfm.org.br/images/stories/biblioteca/bem\%20estar\%20em\%20anestesiologia.pdf>. Acesso em: 08 ago. 2018. 